JOSE ANTONIO APPARECIDO JUNIOR

Métodos e soluções para viabilização jurídica de projetos urbanísticos: papéis públicos e privados

Tese de Doutorado

Orientador: Professor Dr. Sebastião Botto de Barros Tojal

UNIVERSIDADE DE SÃO PAULO

FACULDADE DE DIREITO

SÃO PAULO - SP 
JOSE ANTONIO APPARECIDO JUNIOR

\title{
Métodos e soluções para viabilização jurídica de projetos urbanísticos: papéis públicos e privados
}

\author{
Tese apresentada à Banca Examinadora do \\ Programa de Pós-Graduação em Direito da \\ Faculdade de Direito da Universidade de São \\ Paulo como exigência parcial para obtenção do \\ título de Doutor em Direito, na área de \\ concentração de Direito do Estado, sob orientação \\ do Professor Dr. Sebastião Botto de Barros Tojal.
}

UNIVERSIDADE DE SÃO PAULO

FACULDADE DE DIREITO

SÃO PAULO - SP

2017 
Apparecido Junior, Jose Antonio

Métodos e Soluções para Viabilização Jurídica de Projetos Urbanísticos: Papéis Públicos e Privados / Jose Antonio Apparecido Junior; orientador Sebastião Botto de Barros Tojal -- São Paulo, 2017.

$285 \mathrm{p}$.

Tese (Doutorado - Programa de Pós-Graduação em Direito do Estado) - Faculdade de Direito, Universidade de São Paulo, 2017.

1. Direito urbanístico. 2. Projetos urbanísticos. 3. Processo administrativo. 4. Administração consensual. I. Botto de Barros Tojal, Sebastião, orient. II. Título. 
Nome: APPARECIDO JUNIOR, Jose Antonio

Título: Métodos e soluções para viabilização jurídica de projetos urbanísticos: papéis públicos e privados

Tese apresentada à Faculdade de Direito da Universidade de São Paulo (FDUSP), como exigência parcial para obtenção do título de Doutor em Direito, na área de concentração de Direito do Estado.

Aprovado em:

\section{BANCA EXAMINADORA}

Prof. Dr. Sebastião Botto de Barros Tojal (Orientador) ～Instituição: FDUSP

Assinatura:

Julgamento:

Prof.

Instituição:

Assinatura:

Julgamento:

Prof.

Instituição:

Assinatura:

Julgamento:

Prof.

Instituição:

Assinatura:

Julgamento:

Prof.

Instituição:

Assinatura:

Julgamento:

Prof.

Instituição:

Assinatura:

Julgamento: 


\section{AGRADECIMENTOS}

Sou muito grato. A vida me proporcionou muitas vitórias e derrotas, que me forjaram e me trouxeram até este momento, o da conclusão de um trabalho de doutorado na Faculdade de Direito da Universidade de São Paulo. É uma honra e uma alegria poder vivenciar este instante: me sinto recompensado pelos anos de dedicação, e feliz por ter completado mais este ciclo.

A incrível série de acontecimentos que me trouxe até aqui começou no seio da minha família. Não há como mensurar o quanto devo a estas pessoas. Gente honrada, digna, que me proporcionou as condições para que iniciasse meu caminho, desde a bela e um pouco distante Avaré. Agradeço à minha mãe, Alzira, que sempre será minha referência. À Margarida, que me acolheu em São Paulo, e ajudou a manter meu sonho vivo. À Márcia, olhar sempre presente e carinhoso, que construiu sua história também com muita luta e valentia. A meus sobrinhos William e João Pedro, continuação da vida, que já iniciam sua caminhada. Ao meu pai José, de quem carrego o nome e a história, e que partiu tão cedo, e à minha tia Nele, que junto com a Cidinha e a então pequena e hoje doutora Maria Alice, que fizeram o recémchegado sentir-se em casa. A todos, meu muito obrigado, com muito amor.

Aqui em São Paulo, nos estudos da Faculdade Paulista de Direito da Pontifícia Universidade Católica, além do aprendizado e da formação, tive a imensa alegria de encontrar muitos amigos, a quem agradeço pelas horas de companheirismo, camaradagem e de trabalho. Da sensacional Seiva Jurídica, agradeço ao Fábio Tavares, ao Guilherme Ricci, ao Mauro Spalding, ao Eduardo Siqueira, ao Roberto Contreras, ao Renato Martins e ao Alexandre Moraes, verdadeira legião estrangeira em solo paulistano (Freguesia do Ó é uma cidade a parte), que se uniu e fez coisas tão bacanas no glorioso 22 de Agosto. Na minha nova casa, a Universidade de São Paulo, também tive a felicidade de encontrar amigos que me proporcionaram uma experiência ainda mais rica no doutorado. Agradeço a todos citando os infalíveis Giuliano Deliberador, Emanuel Pessoa, Alexandre Cunha e Fernando Couto. Todos brilhantes, com quem pude aprender muito.

Agradeço também a todos os mestres que tive em minha vida. Sou afortunado, pois sempre encontrei pessoas dedicadas a esta verdadeira missão que é o magistério, e que me auxiliaram em todos os passos nesta caminhada de décadas. É impossível nomear a cada um, mas gostaria, ainda assim, de tecer alguns agradecimentos especiais: primeiramente, à Profa. Lucia Valle Figueiredo, inesquecível educadora, que nos deixou precocemente, e à Profa. 
Daniela Libório, que tão generosamente me acolheu e me permitiu completar o ciclo do mestrado na PUC/SP; agradeço, também, ao Prof. Fernando Menezes de Almeida, raro exemplo em que a gentileza e humildade se ombreiam com a capacidade intelectual, e aos Profs. Vitor Schirato, meu lente mais constante nas disciplinas do doutorado, e Rodrigo Pagani, que transformaram meu exame de qualificação em um momento de ampla revisão e reflexão do trabalho então em curso. Por derradeiro, deixo meu agradecimento às duas pontas desta estrada: à Dona Maria Elisa Martins, minha primeira professora, que me abriu as portas de um mundo totalmente novo, e ao Prof. Sebastião Tojal, que me deu a honra de ser seu orientando no doutorado. Agradeço ao Professor Tojal pela confiança, pela franqueza e pelo auxílio durante todo o meu inesquecível trajeto na Universidade de São Paulo. Espero, sinceramente, ter produzido um trabalho à altura de seu conhecimento e da sua qualidade como educador: muitos dos acertos desta tese são dele; os erros, todos meus.

Ainda no tocante ao processo de produção da tese, tenho dois agradecimentos especiais a fazer. O primeiro ao amigo Alexandre Rocha Almeida de Moraes, que, em mais uma das nossas sempre ricas conversas, acabou disparando as ideias que se transformaram nas linhas gerais deste trabalho. O outro, ao amigo José Fernando Ferreira Brega, que foi incrivelmente paciente, generoso e incansável na revisão do texto, elevando, em muito, seu nível final. Ao amigo que acendeu a luz, e ao outro que iluminou o caminho, minha sincera gratidão.

Agradeço, por fim, à minha esposa Fernanda. Agradeço, primeiramente, pela nova família que me deste, que enche ainda mais de amor minha vida: sua mãe Vanda, que tanto tem nos ajudado na nossa caminhada, sua irmã Juliana, casada com o sensacional Sérgio e pais do lindo Felipe, e ao Ângelo, o avô da nossa pequena. Agradeço, também, pelos anos de dedicação e carinho, e por você ter trazido ao mundo a razão da minha vida, algo que transformou nossa existência de uma forma completa. Por nossa filha Heloísa, e por tanto e tudo que já fizeste por mim e para mim, minha enorme e eterna gratidão. Te amo imensamente. 
Aos grandes amores da minha vida,

Fernanda e Heloísa. 
“Coragem!", animou-me o Mestre. "Não é cedendo ao ócio nem refestelando-se sobre plumas que se conquistam os prêmios de valor. Aquele que à inatividade se entregar, de si deixará sobre a terra memória igual ao traço que fumo risca no ar e a espuma traça na onda. Supera a fadiga, vence o torpor, recobra o ânimo, que das vitórias sobre os perigos, a primeira é a da vontade sobre o corpo".

Dante Alighieri

A Divina Comédia, Canto XXIV 


\section{RESUMO}

APPARECIDO JUNIOR, Jose Antonio. Métodos e soluções para viabilização jurídica de projetos urbanísticos: papéis públicos e privados. 2017. 285 p. Doutorado - Faculdade de Direito, Universidade de São Paulo, São Paulo, 2017.

O presente trabalho propõe-se a analisar métodos e soluções jurídicas para a viabilização de projetos urbanísticos, considerada a alternativa de atuação concertada entre o Poder Público e o setor privado. Para realizar esta tarefa, inicia colacionando fundamentos para a discussão da eficácia dos instrumentos de transformação e qualificação urbana, incluindo o debate sobre o subsistema jurídico-urbanístico brasileiro, formado a partir da Constituição Federal de 1.988, o novo paradigma da atuação consensual da Administração Pública, a propriedade urbana e sua função social e os deveres compartilhados, em termos de desenvolvimento urbano, entre o setor privado e o Estado. Realiza, a seguir, a avaliação do atual estágio da regulação jurídico-urbanística em nosso país, trazendo, além da abordagem de seus aspectos formais, reflexões tendentes a revelar oportunidades para o aprimoramento de sua utilidade no processo de desenvolvimento urbano, especialmente tendo em vista os papéis dos setores público e privado nesta tarefa. Em seguida, identifica, de forma mais específica, fatores que geram ineficiências nos processos de elaboração e implantação dos projetos urbanísticos em nosso país, oferecendo contributos para que os aspectos jurídicos de tais processos sejam aprimorados, destacando-se, dentre estes, a necessidade de ser estabelecido um processo administrativo amplamente público e marcado pela atuação consensual do Poder Público como veículo indispensável à construção e implantação de projetos urbanísticos, e o fortalecimento da atuação estatal na função de arbitrar as disputas havidas na arena de debates referente à formação e aplicação do planejamento urbanístico, bem como do direito urbanístico tendente a implantá-lo. Conclui-se, desta forma, pela possibilidade de aumentarse a eficácia das iniciativas voltadas ao desenvolvimento urbano por meio da implantação de projetos urbanísticos em atuação concertada entre o Poder Público e o setor privado.

Palavras-chave: Direito urbanístico. Projetos urbanísticos. Processo administrativo. Administração consensual. 


\begin{abstract}
APPARECIDO JUNIOR, Jose Antonio. Methods and solutions for the legal feasibility of urban projects: public and private roles. 2017. 285 f. Doctorate - Faculty of Law, University of São Paulo, São Paulo, 2017.
\end{abstract}

The present work intends to analyze legal methods and solutions for the feasibility of urban projects, considered the alternative of concerted action between the Public Power and the private sector. In order to accomplish this task, it begins by collating fundamentals for the discussion about the effectiveness of the instruments for urban transformation and qualification, including the debate on the Brazilian legal-urbanistic subsystem, formed by the Federal Constitution of 1988, the new paradigm of the consensual administrative function, urban property and its social function, and the shared responsibilities, in terms of urban development, between the private sector and the state. It then carries out an evaluation of the current stage of legal-urbanistic regulation in our country, bringing, in addition to the approach to its formal aspects, reflections aimed at revealing opportunities for improving its usefulness in the urban development process, especially with regard to the roles of the public and private sectors in this task. Then, it identifies, in a more specific way, factors that generate inefficiencies in the processes of elaboration and implementation of the urban projects in our country, offering contributions in order to improve the legal aspects of such processes, emphasizing, among these contributions, the need to establish an administrative process widely public and marked by the consensual function of the Public Power as an indispensable vehicle for the construction and implementation of urban projects, and the strengthening of State action in the role of arbitrating the disputes which take place in the arena of debates regarding the formation and implementation of planning, as well as of the urban planning law that should implement it. It is concluded, therefore, that is possible to increase the effectiveness of initiatives aimed at urban development through the implementation of urban projects in a concerted action between the Public Power and the private sector.

Keywords: Urbanistic law. Urbanistic projects. Administrative process. Consensual administration. 


\section{RIASSUNTO}

APPARECIDO JUNIOR, Jose Antonio. Metodi e soluzioni per l'attuabilità giuridica de progetti urbanistici: ruoli pubblici e privati. 2017. 285 p. Dottorato - Facoltá di Giurisprudenza, Università di São Paulo, São Paulo, 2017.

Il presente lavoro si propone di analizzare i metodi e soluzioni legali per la fattibilità di progetti urbani, considerata l'alternativa di concertazione tra il potere pubblico ed il settore privato. Per svolgere questo compito, si comincia con l'esame dei fondamenti per la discussione dell'efficacia degli strumenti di trasformazione e di qualificazione urbana, tra cui il dibattito sul sottosistema legale-urbanistico brasiliano, formato dalla Costituzione federale del 1988, il nuovo paradigma della azione amministrativa consensuale, la proprietà urbana e la sua funzione sociale, e le responsabilità condivise, in termini di sviluppo urbano, tra il settore privato e lo stato. E poi esegue una valutazione della fase attuale di regolamentazione giuridica-urbanistica nel nostro paese, portando, oltre all'approccio ai suoi aspetti formali, riflessioni volte a rivelare le opportunità per migliorare la sua utilità nel processo di sviluppo urbano, soprattutto per quanto riguarda i ruoli dei settori pubblici e privati in questo compito. Poi, si identifica, in modo più specifico, i fattori che generano inefficienze nei processi di elaborazione ed attuazione dei progetti urbani nel nostro paese, oltre que se offrono contributi al fine di migliorare gli aspetti legali di tali processi, sottolineando, tra questi contributi, il bisogno di stabilire un procedimento amministrativo ampiamente pubblico e segnato dalla azione consensuale del potere pubblico come un veicolo indispensabile per la costruzione e l'attuazione di progetti urbani, ed il rafforzamento dell'azione dello Stato nel ruolo di arbitrare le dispute che si svolgono nel campo dei dibattiti sulla formazione ed all'esecuzione dei piani urbanistici, nonché del diritto urbanistico che dovrebbe attuarlo. Si conclude, quindi, che è possibile aumentare l'efficacia delle iniziative volte allo sviluppo urbano attraverso la attuazione di progetti urbani in un'azione concertata tra il potere pubblico ed il settore privato.

Parole chiave: Diritto urbanistico. Progetti urbanistici. Procedimento amministrativo. Amministrazione consensuale. 


\section{SUMÁRIO}

INTRODUÇÃO

\section{CAPÍTULO 1 - FUNDAMENTOS PARA DISCUSSÃO SOBRE A EFICÁCIA DOS PROJETOS URBANÍSTICOS NO BRASIL .................17}

1.1 O direito urbanístico e o dever de instrumentar juridicamente os processos de desenvolvimento urbano

1.1.1 Por que deve haver uma instrumentação jurídica do desenvolvimento urbano? ....21

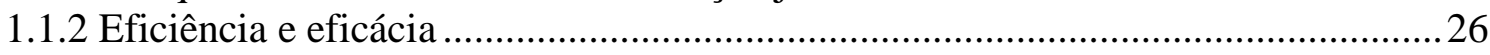

1.1.3 Planejamento urbanístico, planos e projetos urbanísticos, normatividade e processualidade

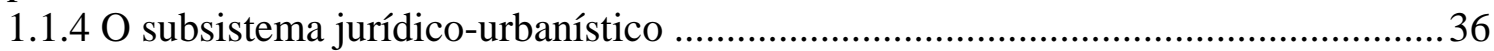

1.1.5 Os princípios fundamentais da Constituição Federal e o direito urbanístico ..........42

1.1.6 A instrumentação jurídica do desenvolvimento urbano e o interesse público a ser tutelado.

1.2 Política de desenvolvimento urbano e a nova forma de atuação da administração pública

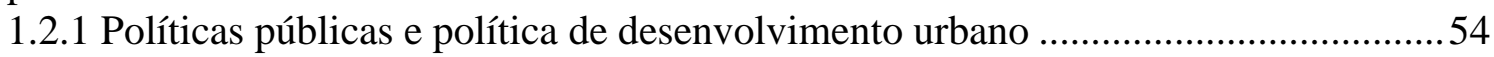

1.2.2 A Escola do Serviço Público e suas relações com o direito urbanístico...................61

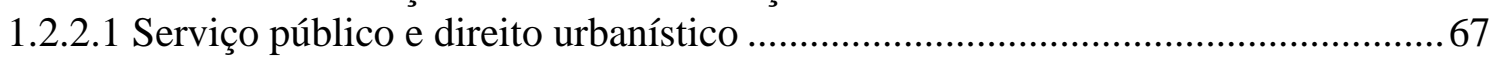

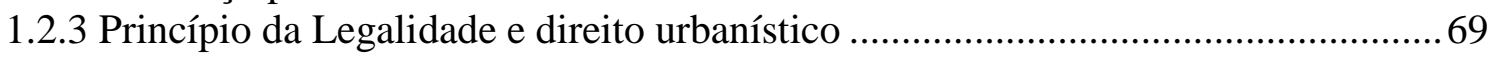

1.3 Propriedade, função social da propriedade e propriedade urbanística....................... 76

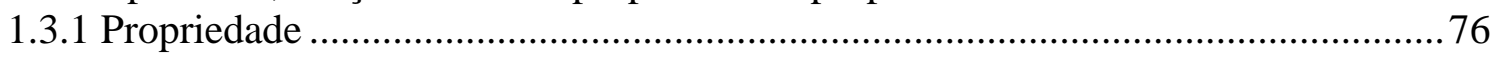

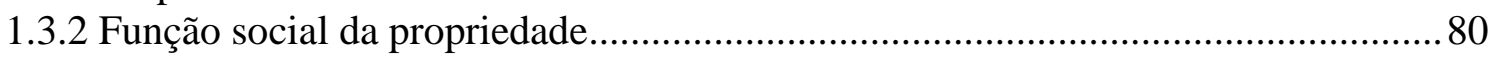

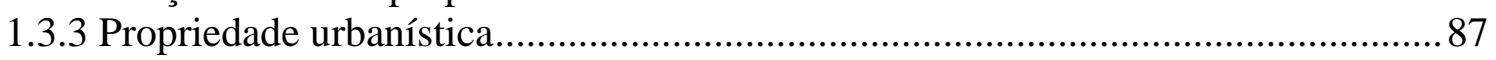

1.4 Livre iniciativa e direito urbanístico: deveres compartilhados ................................. 90

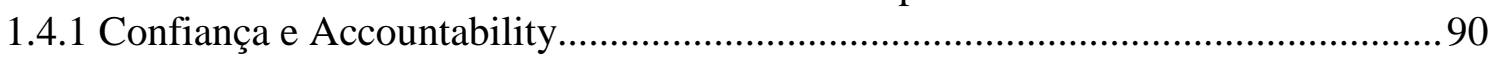

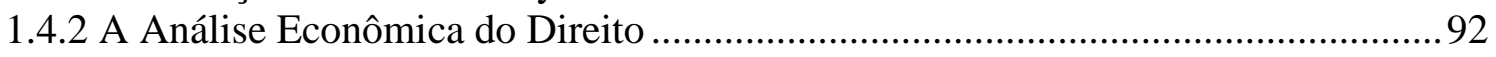

1.4.3 Competências públicas e privadas no desenvolvimento urbano.............................94

\section{CAPÍTULO 2 - OS INSTRUMENTOS JURÍDICO-URBANÍSTICOS NA EXPERIÊNCIA BRASILEIRA ....................................................................... 101}

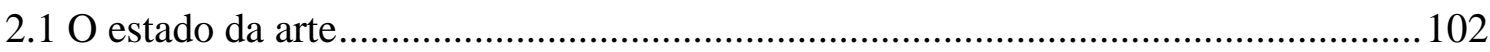

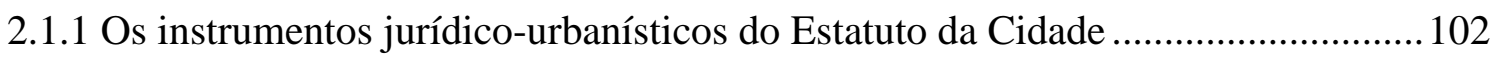

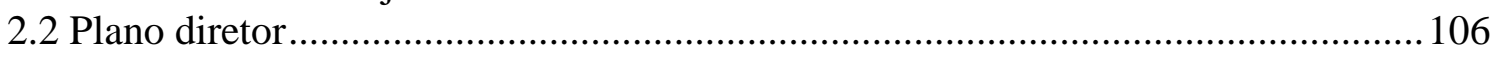

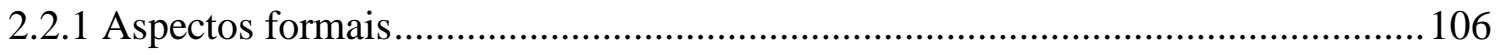

2.2.2 O plano diretor na transformação ou qualificação do território urbano................. 115

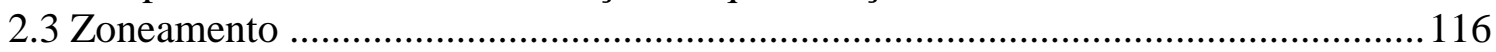

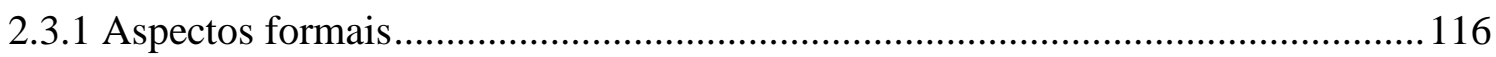

2.3.2 Direito adquirido em face de alteração de zoneamento por nova lei de zoneamento ou por leis especiais 
2.3.3 O zoneamento na transformação ou qualificação do território urbano

2.4 Outorga onerosa de potencial construtivo e transferência de potencial construtivo 125

2.4.1 Preliminarmente: coeficiente de aproveitamento dos lotes e natureza jurídica do potencial construtivo

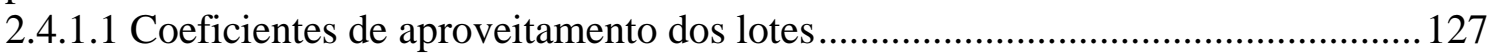

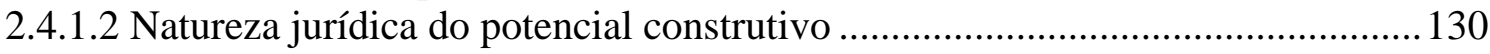

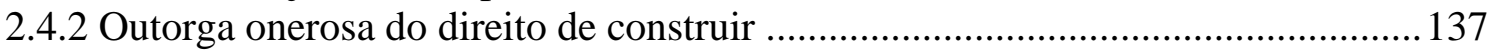

2.4.2.1 Outorga onerosa e os incentivos positivos e negativos ao desenvolvimento urbano

.

2.4.2.2 Quem pode adquirir o potencial construtivo adicional? ................................. 140

2.4.2.3 Contraprestação do particular ao potencial construtivo adicional ..................... 141

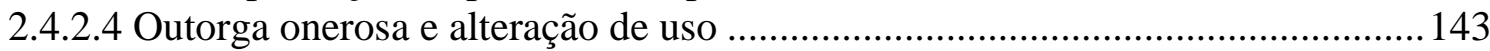

2.4.3 Transferência do direito de construir ................................................................. 144

2.4.3.1 Esclarecimentos preliminares acerca do instrumento da transferência de potencial

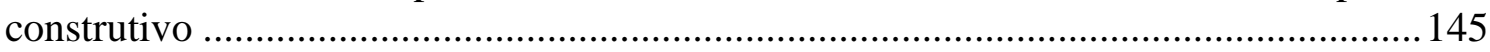

2.4.3.2 A transferência de potencial construtivo e o plano diretor ................................ 147

2.4.3.2.1 Sobre as possibilidades de pleitear a transferência de potencial construtivo dos

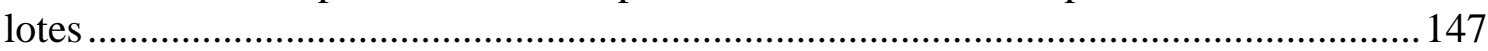

2.4.4 Outorga onerosa de potencial construtivo adicional e transferência de potencial construtivo adicional e a transformação ou qualificação do território urbano................ 154

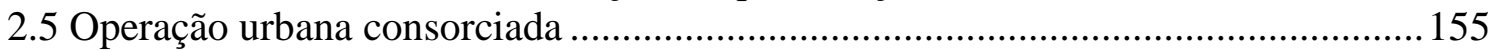

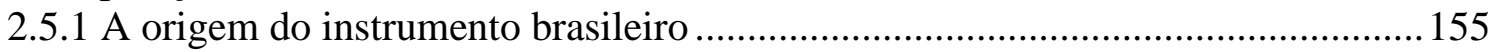

2.5.2 A operação urbana consorciada e o seu projeto urbanístico .................................. 158

2.5.2.1 O programa mínimo do projeto urbanístico da operação urbana consorciada... 162

2.5.3 Os Certificados de Potencial Adicional de Construção - CEPAC ........................ 176

2.5.4 Operação Urbana Consorciada e a transformação ou qualificação do território

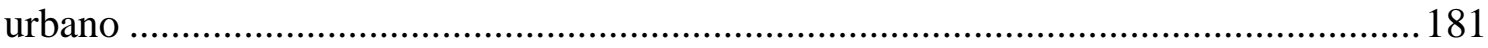

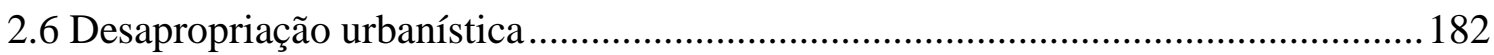

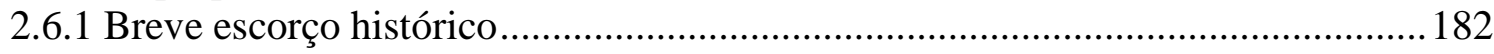

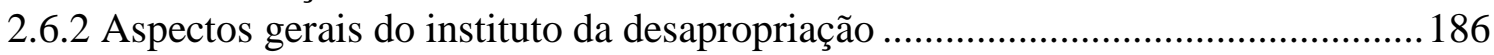

2.6.2.1 Algumas discussões importantes sobre o tema das desapropriações ................... 193

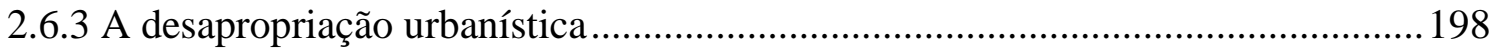

2.6.4 Desapropriações urbanísticas e a transformação ou qualificação do território urbano

2.7 Parcerias público-privadas e concessões urbanísticas ..........................................206

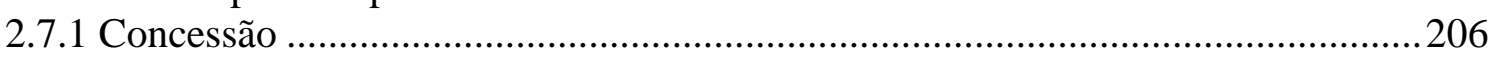

2.7.2. As concessões para transformação ou requalificação urbanística ........................211

2.7.3 A velocidade da implantação da política de desenvolvimento urbano em parcerias

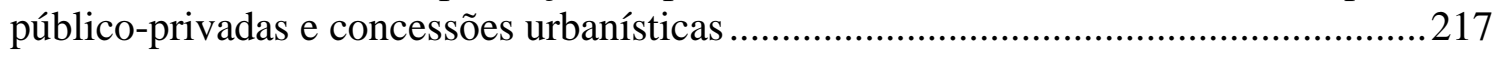

2.7.4 O instrumento nominado "concessão urbanística" ...........................................220

2.7.5 Parcerias público-privadas e concessões urbanísticas e a transformação ou

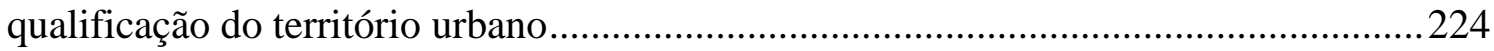

\section{CAPÍTULO 3 - FUNDAMENTOS PARA A EFICÁCIA DOS PROJETOS URBANÍSTICOS .............................................................226}


3.1.1 Indefinição de funções e competências e carências de quadros técnicos na

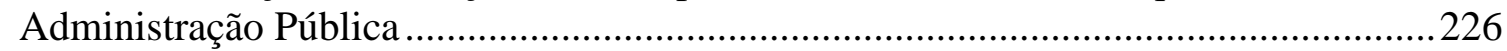

3.1.2 Falta de confiança e déficit de accountability ................................................2235

3.1.3 Base de dados deficientes e estudos ineficientes ..............................................2. 239

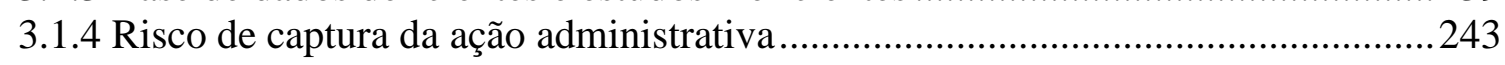

3.1.5 Controle ineficiente da Administração Pública .....................................................246

3.2 O devir: métodos e soluções para viabilização jurídica de projetos urbanísticos....250

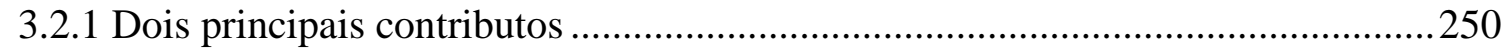

3.2.2 Competências, funções e Reserva de Plano .......................................................253

3.2.3 Informações mais qualificadas, estudos mais eficientes .....................................255

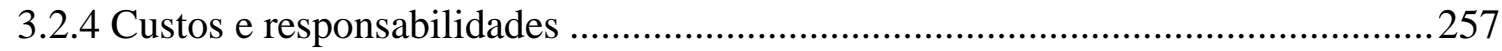

3.2.5 Transparência, accountability e controle .......................................................260

3.2.6 O Poder Público e o setor privado: a busca da eficácia dos projetos urbanísticos 264

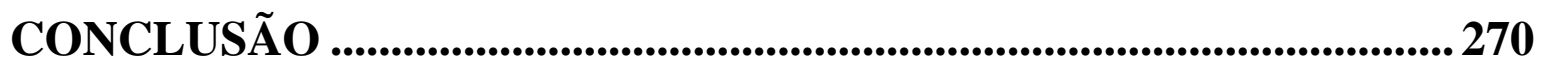

REFERÊNCIAS ................................................................................................. 274 


\section{INTRODUÇÃO}

A Constituição Federal de 1.988 trouxe as disposições básicas da política pública para o desenvolvimento urbano do país. Em seu art. 182, determinou que tal seria executada pelo Poder Público municipal, conforme diretrizes gerais fixadas em lei, com o objetivo de ordenar o pleno desenvolvimento das funções sociais da cidade e garantir o bem-estar de seus habitantes. O instrumento básico eleito a tanto, ainda de acordo com a Carta Magna, foi o plano diretor.

As disposições do texto constitucional, inovadoras em conteúdo, determinaram a necessidade de criação de uma verdadeira agenda de desenvolvimento urbano por parte dos municípios brasileiros. Para dar suporte a tal agenda, e em observância ao disposto no art. 24, inc. I da Constituição Federal, a União editou sua normatização geral no campo do direito urbanístico, o Estatuto da Cidade (Lei n. 10.257, de 10 de julho de 2.001). Tal diploma legal estabeleceu os padrões mínimos pelos quais esta política pública deveria ser elaborada e implantada, criando uma possibilidade de sistematização do direito urbanístico nunca antes delineada. Com efeito, o direito urbanístico, que anteriormente versava eminentemente sobre a regulação de interesses locais - com raras exceções, como a legislação federal referente a parcelamento do solo -, ganhou status de normatização abrangente, com diretrizes e institutos aplicáveis a todo país. A estipulação de diretrizes urbanísticas de observância obrigatória a todos os municípios brasileiros, tendo por objetivo o cumprimento de determinados padrões de desenvolvimento urbano, exsurgiu, desta forma, como característica de um subsistema jurídico de caráter nacional: a partir do Estatuto da Cidade, tornou-se exigível a produção de uma regulação urbanística padronizada e minimamente suficiente a promover as funções sociais da cidade.

É possível afirmar, de outra parte, que o processo de formação e implantação da política pública de desenvolvimento urbano se apresenta como um complexo e dinâmico arranjo, que envolve de forma indissociável o Estado e sociedade. É certo, ainda, que o setor público e os atores privados têm atuações imbricadas na sua conformação (em termos materiais), em sua estruturação jurídico-urbanística e na realização dos efetivos processos de transformação ou qualificação do território, veiculados pelos projetos urbanísticos. A política de desenvolvimento urbano, desta forma, é consubstanciada pelo conjunto coordenado das unidades de planejamento urbanístico - planos e projetos urbanísticos - e construída pela atuação conjunta entre o Poder Público e o setor privado. 
Por outro lado, a despeito das diretrizes, regras, institutos e instrumentos previstos na legislação federal, os municípios brasileiros ainda enfrentam grande dificuldade em transformar o direito urbanístico em uma regulação eficaz no tocante à promoção da qualificação e transformação do território. Tal dificuldade, aponte-se, ocorre a despeito de os processos de planejamento urbanístico serem realizados sob as luzes da normatização jurídico-urbanística instituída a partir do texto constitucional e pelo Estatuto da Cidade já há mais de 15 anos - se é certo que há uma crescente compreensão da importância do plano diretor, e que temas como a regularização fundiária têm tido avanços importantes, os resultados da implantação dos projetos urbanísticos destinados a transformar ou qualificar porções específicas do território dos municípios continuam gerando resultados insatisfatórios.

É importante destacar, neste passo, que o Direito em geral, e especialmente o direito urbanístico, tem hoje como uma de suas principais características o fato de ser um método de composição em realidades complexas, como é o caso da conjugação de esforços entre o setor público e o setor privado na tarefa de desenvolver as cidades. Tendo em vista tal condição, mostra-se pertinente investigar se a observância de determinadas práticas e pressupostos tende a tornar a instrumentação jurídica do desenvolvimento urbano mais eficaz, fazendo com que, por consequência, o próprio planejamento urbanístico esteja mais apto a atingir seus fins. Em outros termos, considerando que o planejamento conforma a multifacetada política de desenvolvimento urbano e que é o direito urbanístico que veiculará a regulação tendente a implantá-lo, insta avaliar se, de fato, é possível a construção de padrões normativos e práticas inspiradas em concepções jurídicas que possibilitem a diminuição das ineficiências inerentes aos processos de elaboração e implantação de projetos urbanísticos, de modo a aumentar as possibilidades de implantação exitosa do planejamento entabulado.

O presente estudo, para tanto, avalia métodos e soluções jurídicas para que haja o aprimoramento da elaboração e implantação dos projetos urbanísticos em nosso país, por intermédio do aumento da eficácia da implantação de seus projetos urbanísticos, especialmente considerando as interações possíveis entre o setor público e o setor privado. Nesta linha de ideias, o trabalho utiliza o método dedutivo para alcançar os objetivos a que se propõe, partindo de premissas detalhadas para estabelecer conclusões sobre o tema investigado. Seu objeto de estudo é o ordenamento jurídico nacional, mais especificamente o subsistema jurídico-urbanístico, sendo sua pesquisa direcionada precipuamente à doutrina 
e às experiências brasileiras sobre o tema. Utiliza, também, referências de projetos urbanísticos já implantados ou em implantação em nosso país, além de colacionar, quando pertinente e útil aos fins do trabalho, experiências estrangeiras sobre o assunto. Para atingir seus objetivos, parte de uma análise teórica, arrolando fundamentos para uma discussão sobre a eficácia da elaboração e implantação dos projetos urbanísticos e sua relação com o instrumental jurídico disponível a tanto, analisa de forma crítica institutos e instrumentos jurídico-urbanísticos brasileiros e, finalmente, identifica elementos que geram ineficiências na elaboração e implantação de projetos urbanísticos em nosso país, propondo métodos e soluções para que haja o aprimoramento do instrumental jurídico destes processos, especialmente considerando os papéis dos atores públicos e privados envolvidos.

O tema tratado neste trabalho, verifica-se, tem grande importância no cotidiano da população brasileira, especialmente das grandes e médias cidades. Demanda, portanto, atenção da ciência jurídica, que deve oferecer fundamentos para que o direito urbanístico possa, de fato, auxiliar na busca do ideal de cidades cada vez mais sustentáveis, com um desenvolvimento equilibrado e justo. 


\section{CONCLUSÃO}

O estímulo inicial à elaboração do presente trabalho foi a constatação de que, mesmo depois de 15 anos de vigência do Estatuto da Cidade, em que pese haver avanços em pontos como o respeito ao plano diretor e nas questões referentes à regularização fundiária e moradia de interesse social, os resultados práticos da implantação de projetos urbanísticos em nosso país ainda são bastante tímidos. A despeito de todo esforço realizado pelos entes federados, pela sociedade civil organizada e até mesmo pelos setores da economia diretamente interessados, a concretização do ideal de desenvolvimento urbano sustentável ainda se encontra longe de ser alcançado pelos municípios brasileiros, sendo parte deste problema a ineficácia do instrumental jurídico-urbanístico estabelecido para dar cumprimento a esta tarefa nos processos destinados à qualificação ou transformação de parcelas do território, veiculados no bojo de projetos urbanísticos.

Tendo em vista tal panorama, o trabalho procurou analisar se o aperfeiçoamento do instrumental técnico-jurídico seria capaz de tornar mais eficazes os processos de implantação de projetos urbanísticos, e, por consequência, a concretização da política de desenvolvimento urbano do município como um todo. Como método, avaliou, a partir da visão das relações entre o setor público e o setor privado na execução das atividades urbanísticas, as razões de tal ineficácia, propondo contributos para o aprimoramento dos processos de elaboração e implantação dos projetos urbanísticos.

Nestes termos, o Capítulo 1 iniciou oferecendo fundamentos para a discussão sobre a eficácia dos projetos urbanísticos no Brasil. Seu desenvolvimento trouxe elementos que versaram sobre a atual conformação da atividade administrativa em nosso país, e, de forma específica, acerca das atividades urbanísticas de elaboração e implantação de projetos urbanísticos. Constatada a existência de um subsistema jurídico de direito urbanístico no Brasil, baseado na Constituição Federal e com suas linhas gerais estabelecidas pelo Estatuto da Cidade, avaliaram-se as especificidades em sua leitura e aplicação. Da mesma forma, foi realizada uma análise da metodologia de produção e implantação do direito urbanístico tendo em vista o novo paradigma de atuação consensual da Administração Pública, indissociavelmente conectado à adoção da processualidade como forma de encaminhamento e decisão de demandas. Neste momento, verificada a importância dos diversos atores intervenientes na formação e aplicação da política de desenvolvimento urbano, já foi possível destacar a importância do papel de árbitro, a ser exercido pelo Poder Público, na 
definição dos interesses públicos a privilegiar nos processos de elaboração e implantação de planos e projetos urbanísticos.

O Capítulo 2 trouxe reflexões sobre o "estado da arte" da regulação jurídicourbanística no Brasil. Cada análise realizada, tanto dos instrumentos de planejamento mais gerais (o plano diretor e o zoneamento) como dos instrumentos jurídico-urbanísticos destacados em seu conteúdo, foi encerrada com breves observações sobre seu papel na transformação ou qualificação do território urbano. O Capítulo 2 revelou aspectos que evidenciam tanto pontos já devidamente incorporados à técnica de utilização dos instrumentos jurídico-urbanísticos como questões ainda pendentes em seus processos de formação e de aplicação. Mais que uma simples leitura sobre os aspectos formais do ordenamento jurídico-urbanístico, foram realizadas reflexões tendentes a revelar oportunidades para o aprimoramento de sua utilidade no processo de elaboração e implantação de projetos urbanísticos, especialmente tendo em vista os papéis dos setores público e privado nesta tarefa.

A partir dos elementos anteriormente coligidos, o Capítulo 3 buscou inicialmente identificar de forma mais específica fatores que geram ineficiências nos processos de elaboração e implantação de projetos urbanísticos, tornando-os menos eficazes ou mesmo ineficazes quanto aos seus fins. Foram apresentados, em seguida, contributos para que os aspectos jurídicos em tais processos fossem aprimorados, de modo a diminuir ou mesmo elidir as causas geradoras das apontadas ineficiências. O objetivo de tais contribuições foi o de apresentar métodos e soluções voltados a buscar o aumento da eficácia do processo de implantação dos projetos urbanísticos, especificamente analisando como tal aprimoramento tem reflexos nas atuações dos diversos atores intervenientes em seus ciclos de formação e concretização.

O último capítulo deste trabalho apresentou um subtítulo que contém o verbo "devir", que significa transformação, o que virá a ser. Sem que haja qualquer pretensão de imaginar ser este estudo uma ampla compilação de todas as possibilidades de aprimoramento do instrumental jurídico utilizável para a elaboração e implantação de projetos urbanísticos, foi proposto um percurso que tivesse como ponto culminante arrolar alguns métodos e soluções úteis a auxiliar a melhoria dos resultados advindos do tremendo esforço realizado pela sociedade brasileira na função de transformar ou qualificar o território de suas grandes e médias cidades por intermédio de tais projetos. 
De fato, em que pesem os esforços dos municípios brasileiros para a confecção e implantação de projetos urbanísticos para a qualificação ou transformação do território, com dezenas de milhões de reais gastos e anos de esforço das Administrações Públicas despendidos nesta tarefa, pouco há a comemorar neste campo. O êxito no alcance dos objetivos inicialmente propostos é raro, não sendo incomum a situação de projetos que, a despeito de terem sido concluídos, nem sequer tiveram sua implantação iniciada. Ainda que se reconheça que o Direito, por si, não é capaz de transformar este quadro, que guarda complexidade muito maior que a da simples regulação jurídica aplicável a tais processos, sem dúvida que a ciência jurídica deve oferecer elementos para auxiliar em sua solução. Não basta à ciência do Direito, em outras palavras, simplesmente descrever tal fenômeno, identificando suas razões e consequências: trata-se, isto sim, de propor métodos e soluções jurídicas que auxiliem na construção de uma nova realidade para este fenômeno.

O principal móvel para o cumprimento desta verdadeira missão, por sua vez, está na própria sociedade, que hoje manifesta sua intenção de não somente exercer um controle burocrático e formal da formulação da política de desenvolvimento urbano como, e sim de influenciar em sua conformação e implantação. Mais que o desejo de realizar contribuições técnicas, ou de ser meramente informada dos processos em andamento, há o anseio pela democratização da política de desenvolvimento urbano, com a instituição de canais de diálogo com um Poder Público responsivo, atendendo-se, assim, ao exigido pelo subsistema jurídico-urbanístico existente em nosso país.

Sob outro aspecto, existe a necessidade, do ponto de vista pragmático, de que o setor privado esteja em permanente contato com a formação da convicção administrativa acerca da normatização urbanística. A identificação de suas demandas e aspirações no tocante às decisões referentes aos projetos urbanísticos é capaz de auxiliar a produção de um instrumental jurídico-urbanístico mais adequado à implantação de tais projetos, com maior utilidade aos fins a que se destina. Mais que isso, o reconhecimento de que há uma arena pública de disputa pelas decisões referentes à política de desenvolvimento urbano, em que interesses legítimos de diversos atores se contrapõem, justapõem ou se identificam, evidencia que, ao lado da inafastável prerrogativa da Administração Pública de definir os elementos fundamentais do planejamento urbanístico e impor a normatização a partir destas decisões, há o direito do setor privado de tentar influenciar a formação desta convicção. Os métodos e soluções para viabilização jurídica de projetos urbanísticos, desta forma, têm o dever de considerar estas relações e de sintetizar os processos dialéticos nelas estabelecidos. 
Dentre tais métodos e soluções, por sua vez, alguns se oferecem mais evidentes, outros menos óbvios. Desta forma, ao lado da identificação da necessidade de estabelecer uma processualidade inerente à execução da política de desenvolvimento urbano, ilustrada pelas técnicas da consensualidade e transparência no processo de formação da convicção administrativa sobre a elaboração e implantação de planos e projetos urbanísticos, apontouse a necessidade de qualificação dos quadros técnicos da Administração Pública para que estejam aptos à execução de tais tarefas; da mesma maneira, ao mesmo tempo em que se constata, em distintas situações, a necessidade fortalecer a capacidade do Poder Público para cumprir sua missão de identificar e determinar as medidas jurídicas necessárias a gerar eficácia na formulação e implantação dos projetos urbanísticos, arbitrando as disputas de interesses havidas na arena pública de discussões sobre o tema, identificou-se útil ao aprimoramento do instrumental jurídico-urbanístico referente aos planos urbanísticos que os controles exercidos sobre a Administração Pública na tarefa de elaborar e implantar projetos urbanísticos sejam qualificados também pelo diálogo e troca de informações entre órgãos controlados e controladores.

O trabalho, assim, a partir de elementos pertinentes ao conhecimento teórico e prático, avançou dialeticamente na identificação dos problemas que geram ineficiências na elaboração e implantação de projetos urbanísticos e, com base em uma leitura dos papéis dos setores públicos e privados nesta tarefa, propôs métodos e soluções para sua resolução. A transformação da técnica de elaboração e implantação de projetos urbanísticos no Brasil, por fim, parece estar em curso, tendo este trabalho o objetivo de oferecer elementos que auxiliem a melhorar a eficácia dos instrumentos jurídico-urbanísticos necessários ao cumprimento desta importante tarefa. 


\section{REFERÊNCIAS}

ALENCAR, Letícia Oliveira Lins de. A atividade administrativa de fomento e a importância do planejamento. Forum Administrativo. Belo Horizonte: Forum, ano 16, n. 182, p. 25-40, abr. 2016.

ALOCHIO, Luiz Henrique Antunes. Do solo criado (Outorga Onerosa do Direito de Construir): instrumento de tributação para a ordenação do ambiente urbano. Rio de Janeiro: Lumen Juris, 2005.

. Plano Diretor Urbano e Estatuto da Cidade: Medidas cautelares e moratórias urbanísticas. Belo Horizonte: Fórum, 2010.

ANGARITA, Antônio. Estado e empresa: uma relação imbricada. 1. ed. São Paulo: Direito GV, 2013.

AMARAL, Gustavo; MELO, Daniele. Há direitos acima dos orçamentos? In: SARLET, Ingo Wolfgang; TIMM, Luciano Benetti (orgs.). Direitos Fundamentais: orçamento e "reserva do possível". 2. ed. Porto Alegre: Livraria do Advogado, 2010.

ANTUNES ROCHA, Carmen Lúcia. O princípio constitucional da função social da propriedade. In: BACELLAR, Romeu Felipe; FERREIRA MOTTA, Paulo Roberto; AGUIRRE DE CASTRO, Rodrigo Pironti (coords.). Direito Administrativo Contemporâneo. Belo Horizonte: Fórum, 2005.

APPARECIDO JÚNIOR, José Antônio. O uso tolerado: regra de transição isonômica no plano urbanístico. Forum Municipal \& Gestão das Cidades (FMGC), Belo Horizonte: Forum, ano 1, n. 2, p. 34., nov/dez 2013.

Propriedade Urbanística e Edificabilidade. Curitiba: Juruá, 2012.

Plano Diretor como parâmetro de aferição de validade material das leis urbanísticas municipais. Revista dos Tribunais São Paulo: RTSP. São Paulo: Revista dos Tribunais, v. 2, n. 5-6, p. 71-96, mar-abr/maio-jun 2014.

ARAGÃO, Alexandre Santos de. Direito dos Serviços Públicos. 3. ed. Rio de Janeiro: Forense, 2013.

O princípio da proporcionalidade no direito econômico. São Paulo: Revista dos Tribunais, 2002. $800 \mathrm{v}$.

O Princípio da Eficiência. Revista Eletrônica de Direito Administrativo Econômico. Salvador: Instituto de Direito Público da Bahia, n. 4, nov/dez 2005, jan 2006.

ARIMATÉA, José Rodrigues. O Direito de Propriedade: imitações e restrições públicas. Franca: Lemos e Cruz, 2003. 
AUBY, Jean_Bernard; PÉRINET-MARQUET, Hugues; NOGUELLOU, Rozen. Droit de l'urbanisme et de la construcion. 8. ed. Paris: L.G.D.J, 2008.

ÁVILA, Ana Paula Oliveira. O Princípio da Impessoalidade na Administração Pública: Para uma Administração Imparcial. Rio de Janeiro: Renovar, 2004.

ÁVILA, Humberto Bergmann. Repensando o princípio da supremacia do interesse público sobre o particular. Revista Trimestral de Direito Público (RTDP). São Paulo: Malheiros, n. 24, p. 159-180, 1999.

AZEVEDO MARQUES, Floriano de Azevedo. Bens públicos: função social e exploração econômica - o regime jurídico das utilidades públicas. Belo Horizonte: Fórum, 2009.

BANDEIRA DE MELLO, Celso Antônio. Curso de Direito Administrativo. 30. ed. São Paulo: Malheiros, 2013.

Novos Aspectos da função social da propriedade no direito público. Revista de Direito Público, v. 20, n. 84, out/dez 1987.

BALSAS, Carlos Jose Lopes. O urbanismo comercial e as parecerias público-privado. Lisboa: Gabinete de Estudos e Prospectiva Econômica, 2002.

BARCELlOS, Ana Paula de. Constitucionalização das políticas públicas em matéria de direitos fundamentais: o controle político-social e o controle jurídico no espaço democrático. In: SARLET, Ingo Wolfgang; TIMM, Luciano Benetti (orgs.). Direitos Fundamentais: orçamento e "reserva do possível". 2. ed. Porto Alegre: Livraria do Advogado, 2010.

BARROSO, Luís Roberto. A Constitucionalização do Direito e o Direito Civil. In: TEPEDINO, Gustavo (org.). Direito Civil Contemporâneo: Novos problemas à luz da legalidade constitucional. São Paulo: Atlas, 2008.

Curso de Direito Constitucional Contemporâneo: os conceitos fundamentais e a construção do novo modelo. 5. ed. São Paulo: Saraiva, 2015.

BASTOS, Celso. Curso de Teoria do Estado e Ciência Política. 5. ed. São Paulo: Celso Bastos Editora, 2002.

BINENBOJM, Gustavo. Poder de polícia, Ordenação, Regulação. Transformações político-jurídicas, econômicas e institucionais do direito administrativo ordenador. Belo Horizonte: Fórum, 2016.

2014.

Uma teoria do direito administrativo. 3. ed. rev. e atual. Rio de Janeiro: Renovar,

BOBBIO, Norberto. Da estrutura à função: novos estudos de teoria do Direito. Barueri: Manole, 2007.

O positivismo jurídico: lições de filosofia do direito. São Paulo: Ícone, 2006.

Teoria do ordenamento jurídico. 5. ed. Brasília: Universidade de Brasília, 1994. 
BOCKMANN MOREIRA, Egon; GUIMARÃES, Fernando Vernalha. A Lei Geral de Licitação - LGL e o Regime Diferenciado de Contratação - RDC. 4. ed. rev. e aum. São Paulo: Malheiros, 2012.

Processo Administrativo. Princípios constitucionais e a Lei 9.784/1999. 4. ed. atual. rev. e aum. São Paulo: Malheiros, 2010.

Qual é o futuro do direito da regulação no Brasil? In: SUNDFELD, Carlos Ari; ROSILHO, André (orgs.). Direito da Regulação e Políticas Públicas. São Paulo: Malheiros, 2014.

BORGES, Alice Gonzalez. Operações urbanas consorciadas: os consórcios intermunicipais como instrumento de realização do Estatuto da Cidade. In: WAGNER JUNIOR, Luiz Guilherme da Costa (coord.). Estudos em homenagem ao Professor Adilson Abreu Dallari. Belo Horizonte: Del Rey, 2004.

BREGA, José Fernando Ferreira. O público e o privado na implantação de planos de renovação urbana. Revista de Direito Administrativo Contemporâneo, São Paulo: Revista dos Tribunais. v. 4, jan. 2014.

BUCCI, Maria Paula Dallari. Fundamentos para uma teoria jurídica das políticas públicas. São Paulo: Saraiva, 2013.

. O Conceito de política pública em direito. In: BUCCI, Maria Paula Dallari (Coord.). Políticas Públicas. Reflexões sobre o conceito jurídico. São Paulo: Saraiva, 2006.

Políticas públicas e direito administrativo. Brasília: Revista de Informação Legislativa, 1997.

BULOS, Uadi Lammêgo. Curso de Direito Constitucional. 8. ed. São Paulo: Saraiva, 2014.

CANARIS, Claus-Wilhelm. Pensamento sistemático e conceito de sistema na ciência do direito. 4. ed. Lisboa: Fundação Calouste Gulbenkian, 2008.

CANOTILHO, José Joaquim Gomes. Direito Constitucional e Teoria da Constituição. 7. ed. Coimbra: Almedina, 2003.

CARDOSO, Fernanda Lousada. A Propriedade Privada Urbana Obriga?. São Paulo: Renovar, 2008.

CARVAlHO FILHO, José dos Santos. Comentários ao Estatuto da Cidade. 5. ed. São Paulo: Atlas, 2013.

Plano Diretor e Inconsciência Urbanística. In: MARQUES NETO, Floriano de Azevedo; MENEZES DE ALMEIDA, Fernando; NOHARA, Irene Patrícia; MARRARA, Thiago (orgs.). Direito e Administração Pública: Estudos em homenagem a Maria Sylvia Zanella Di Pietro. São Paulo: Atlas, 2013. 
CARVALHO PINTO, Victor. Direito Urbanístico: plano diretor e direito de propriedade. 4. ed. rev. atual. e ampl. São Paulo: Revista dos Tribunais, 2014.

CASSESE, Sabino. A Crise do Estado. Campinas: Saber, 2010.

CASTRO, José Nilo de. Planejamento cidadão. In: WAGNER JUNIOR, Luiz Guilherme da Costa (coord.). Estudos em homenagem ao Professor Adilson Abreu Dallari. Belo Horizonte: Del Rey, 2004.

CAVALCANTI, Themístocles Brandão. Teoria do Estado. Rio de Janeiro: Borsoi, 1969.

CHEVALLIER, Jacques. Science administrative. 2 ed. Paris: PUF, 1994.

CLÉVE, Clèmerson Merlin. Temas de direito constitucional. 2. ed. rev. atual. e ampl. Belo Horizonte: Fórum, 2014.

COORDENADORIA GERAL DE PLANEJAMENTO (COGEP). Política Global de Desenvolvimento Urbano e Melhoria da Qualidade de Vida. São Paulo: Prefeitura Municipal de São Paulo, 1980.

CORREIA, Fernando Alves. Manual de Direito do Urbanismo. 4. ed. Coimbra: Almedina, 2008. $1 \mathrm{v}$.

. O Plano Urbanístico e o Princípio da Igualdade. Coimbra: Almedina, 2001.

COSTA, Regina Helena. A contribuição de melhoria como instrumento de política urbana. In: WAGNER JUNIOR, Luiz Guilherme da Costa (coord.) Estudos em homenagem ao Professor Adilson Abreu Dallari. Belo Horizonte: Del Rey, 2004.

COUTO E SILVA, Clóvis Veríssimo. Contrato de Engineering. São Paulo: Revista dos Tribunais, ano 81, v. 685, 1992.

CUNHA FILHO, Alexandre Jorge Carneiro da. Poder de Polícia: compreensão contemporânea do instituto e discussão sobre a possibilidade de delegação de seu exercício a entes privados. Ribeirão Preto: IELD, 2014.

DALLARI, Adilson Abreu. Alterações dos contratos administrativos - economicidade, razoabilidade e eficiência. Revista Trimestral de Direito Público. São Paulo: Malheiros, n. 40, 2002.

Concessões Urbanísticas. In: FREITAS, José Carlos de (coord.). Temas de Direito Urbanístico 3. São Paulo: Imprensa Oficial do Estado/Ministério Público do Estado de São Paulo, 2001.

Instrumentos da Política Urbana. In: DALLARI, Adilson Abreu; FERRAZ, Sérgio (coords.). Estatuto da Cidade (Comentários à Lei Federal 10.257/2001). 4. ed. São Paulo: Malheiros, 2014. 
DIAS, Reinaldo; MATOS, Fernanda. Políticas públicas: Princípios, propostas e processos. São Paulo: Atlas, 2012.

DINIZ, Maria Helena. Código Civil Anotado. 15. ed. São Paulo: Saraiva, 2010.

_ Compêndio de introdução à ciência do direito. 20. ed. São Paulo: Saraiva, 2009. 2010. Curso de Direito Civil Brasileiro 4 - Direito das Coisas. 25. ed. São Paulo, Saraiva,

DI PIETRO, Maria Sylvia Zanella. Direito Administrativo. 27. ed. São Paulo: Atlas, 2014.

. Função social da propriedade pública. In: WAGNER JUNIOR, Luiz Guilherme da Costa (coord.). Estudos em homenagem ao Professor Adilson Abreu Dallari. Belo Horizonte: Del Rey, 2004.

- Parcerias na Administração Pública: Concessão, Permissão, Franquia, Terceirização, Parceria Público-Privada e Outras Formas. 10. ed. São Paulo: Atlas, 2015.

DWORKIN, Ronald. Levando os direitos a sério. São Paulo: Martins Fontes, 2010.

ENGISCH, Karl. Introdução ao Pensamento Jurídico. 10. ed. Lisboa: Fundação Calouste Gulbenkian, 2008.

ENTERRÍA, Eduardo Garcia de; FERNÁNDEZ, Tomás-Ramón. Curso de Derecho Administrativo I. 15. ed. Madrid: Thomson-Reuters, 2011.

ENTERRÍA, Eduardo Garcia de. Democracia, Jueces y Control de la Administracion. 5. ed. Madrid: Civitas, 2000.

ESCOLA, Hector Jorge. El interés público como fundamento del Decrecho Administrativo. Buenos Aires: De Palma, 1989.

FAGUNDES, Miguel Seabra. O controle dos atos administrativos pelo Poder Judiciário. São Paulo: Saraiva, 1984.

FARIAS, Márcia. O direito urbanístico e o direito de propriedade norte-americanos: planejamento urbano e desapropriação para fins de interesse público após a decisão no caso "Kelo vs. City of New London". Interesse Público: Revista bimestral de direito público. Porto Alegre: Editora Notadez, ano 8, n. 40, p. 179-196, nov/dez 2006.

FERNÁNDEZ, Tomás-Ramón. Curso de Derecho Administrativo I. 15. ed. Madrid: Thomson-Reuters, 2011.

FIGUEIREDO, Leonardo Vizeu. Lições de Direito Econômico. 8. ed. Rio de Janeiro: Forense, 2015.

FIGUEIREDO, Lucia Valle. Curso de Direito Administrativo. 9. ed. rev. atual. e ampl. São Paulo: Malheiros, 2008.

Disciplina Urbanística da Propriedade. 2. ed. São Paulo: Malheiros, 2005. 
FURTADO, Fernanda; MALERONKA, Camila. Concesión onerosa del derecho de construir (OOCD por su siglas em portugués): la experiencia de São Paulo en la gestión pública de las edificabilidades. In: FURTADO, Fernanda; SMOLKA, Martin O. Instrumentos Notables de políticas de suelo nm América Latina. Quito: Lincoln Institute of Land Policy, 2014.

GARCIA, Fernando Couto. A desapropriação por hasta pública no ordenamento jurídico português e a constitucionalidade da proposta de sua introdução no direito brasileiro. São Paulo: Revista dos Tribunais, v. 5, p. 305-325, mar/abr 2014.

GIANNINI, Massimo Severo. Diritto Amministrativo, volume primo. Milão: Giufré, 1970.

GONÇALVES, Pedro. Entidades privadas com poderes públicos: o exercício de poderes públicos de autoridade por entidades privadas com funções administrativas. Coimbra: Almedina, 2005.

GORDILlO, Augustin. Princípios Gerais de Direito Público. São Paulo: Revista dos Tribunais, 1997.

Tratado de Derecho Administrativo. Tomo I. Parte General. 7. ed. Belo Horizonte: Del Rey e Fundación de Derecho Administrativo, 2003.

GRAU, Eros Roberto. A ordem econômica na Constituição de 1988: interpretação e crítica. 7. ed. São Paulo: Malheiros, 2002.

2014.

O Direito Posto e o Direito Pressuposto. 9. ed. rev. e ampl. São Paulo: Malheiros,

GROTTI. Dinorá Adelaide Musetti. A Participação Popular e a Consensualidade na Administração Pública. In: MOREIRA NETO, Diogo de Figueiredo. Uma Avaliação das Tendências Contemporâneas do Direito Administrativo. Rio de Janeiro, Renovar, 2003.

2003.

O serviço público e a Constituição Brasileira de 1988. São Paulo: Malheiros,

HUMBERT, George Louis Hage. O Direito urbanístico e a função socioambiental da propriedade urbana. Belo Horizonte: Fórum, 2009.

IGNATIOS, Marcelo Fonseca; MONTANDON, Daniel Todmann. A dimensão urbanística da Outorga Onerosa do Direito de Construir no Município de São Paulo. Lincoln Institute of Land Policy,Working Paper, 2016.

INSTITUTO BRASILEIRO DE GEOGRAFIA E ESTATÍSTICA (IBGE). Tendências Demográficas: uma análise da população com base nos censos demográficos de 1940 e 2000. Disponível em: <http://www.ibge.gov.br/home/estatistica/populacao/tendencia demografica/analise_populacao/1940_2000/analise_populacao.pdf $>$. Acesso em: 23 abr. 2016. 
JAMPAULO JUNIOR, João. Plano diretor: o processo legislativo. In: DALLARI, Adilson Abreu; LIBÓRIO, Daniela Campos. Direito Urbanístico e Ambiental. Belo Horizonte: Forum, 2007.

JUSTEN FILHO, Marçal. Concessões Urbanísticas e outorgas onerosas. In: WAGNER JUNIOR, Luiz Guilherme da Costa (coord.). Estudos em homenagem ao Professor Adilson Abreu Dallari. Belo Horizonte: Del Rey, 2004.

KELSEN, Hans. Teoria Geral do Direito e do Estado. 4. ed. Martins Fontes: São Paulo, 2005 .

Direito ao Desenvolvimento da Constituição Brasileira de 1988. Revista Eletrônica de Direito Administrativo e Econômico. Salvador: Bahia, n. 16, p. 10-12, nov/dez/jan 2009.

LEITE, Carlos. Cidades sustentáveis, cidades inteligentes. Porto Alegre: Bookman, 2012.

LEME MACHADO, Paulo Affonso. Direito Ambiental Brasileiro. 17. ed. rev. atual. e ampl. São Paulo: Malheiros, 2009.

LEVIN, Alexandre. Operação urbana consorciada: concertação público-privada para a justa distribuição dos benefícios decorrentes da atividade urbanística. Rio de Janeiro: Lumen Juris, 2014.

LIBÓRIO, Daniela Campos. Bem ambiental, livre iniciativa e interesse público. In: MARQUES NETO, Floriano de Azevedo; MENEZES DE ALMEIDA, Fernando; NOHARA, Irene Patrícia; MARRARA, Thiago (orgs.). Direito e Administração Pública Estudos em homenagem a Maria Sylvia Zanella di Pietro. São Paulo: Atlas, 2013.

Elementos de Direito Urbanístico. São Paulo: Manole, 2004.

LIMONGI FRANÇA, Rubens. A irretroatividade das leis e o direito adquirido. 3. ed. São Paulo: Revista dos Tribunais, 1982.

LOMAR, Paulo José Villela. Operação Urbana Consorciada. In: DALLARI, Adilson Abreu; Ferraz, Sérgio (coords.). Estatuto da Cidade (Comentários à Lei Federal n. 10.257/2001). 4. ed. São Paulo: Malheiros, 2014.

LOUREIRO, Francisco Eduardo. A Propriedade como Relação Jurídica Complexa. Rio de Janeiro: Renovar, 2003.

MACIEL, Fabianne Manhães. Direito da cidade e função social da cidade. In: MOTA, Maurício; TORRES, Marcos Alcino. Transformações do Direito de Propriedade Privada. Rio de Janeiro: Elsevier, 2009.

MACHADO HORTA, Raul. Estudos de direito constitucional. Belo Horizonte: Del Rey, 1995. 
MACLAREN, Virginia W. Urban Sustainability Reporting. In: WHEEELER, Stephen M.; BEATLEY, Timothy. The Sustainable Urban Development Reader. London: Routledge, 2004.

MAFFINI, Rafael. Princípio da Proteção Substancial da Confiança no Direito Administrativo Brasileiro. Porto Alegre: Verbo Jurídico, 2006.

MALERONKA, Camila. Projeto e gestão na metrópole contemporânea: um estudo sobre as potencialidades do instrumento 'operação urbana consorciada' à luz da experiência paulistana. 245 p. Tese (Doutorado em História e Fundamentos da Arquitetura e do Urbanismo) - FAUUSP, São Paulo, 2010.

MALUF, Adriana Caldas do Rego Freitas Dabus. Limitações Urbanas ao Direito de Propriedade. São Paulo: Atlas, 2010.

MARÉS, Carlos Frederico. A Proteção Jurídica dos bens culturais. Revista de Direito Constitucional e Internacional, v. 2, jan/mar 1993.

MARQUES NETO, Floriano de Azevedo. A contratação de particulares para suporte de atividade regulatória estatal. Revista Trimestral de Direito Público. São Paulo: Malheiros, n. 32, 1993.

Bens Públicos: função social e exploração econômica. O regime jurídico das utilidades públicas. Belo Horizonte: Fórum, 2009.

Concessões. Belo Horizonte: Fórum, 2015.

. Outorga onerosa do direito de construir. In: DALLARI, Adilson Abreu; FERRAZ, Sérgio (coords.). Estatuto da Cidade (Comentários à Lei Federal 10.257/2001). 4. ed. São Paulo: Malheiros, 2014.

Os grandes desafios do controle da Administração Pública. Fórum de Contratação e Gestão Pública. Belo Horizonte: Fórum, ano 9, n. 100, p. 12-13, abr. 2010.

Regulação estatal e interesses públicos. São Paulo: Malheiros, 2002.

MARRARA, Thiago. Bens públicos, Domínio urbano e Infraestruturas. Belo Horizonte: Fórum, 2007.

MAURER, Hartmut. Elementos de direito administrativo alemão. Porto Alegre: Safe, 2001.

MEDAUAR, Odete. Controle da Administração Pública. 3. ed. rev. atual. e ampl. São Paulo: Revista dos Tribunais, 2014.

O direito administrativo em evolução. 2. ed. rev. atual. e ampl. São Paulo: Revista dos Tribunais, 2003.

Direito Administrativo Moderno. 18. ed. rev. e atual. São Paulo: Revista dos Tribunais, 2014. 
MEIRELLES, Hely Lopes. Direito de Construir. 10. ed. São Paulo: Malheiros, 2011.

MENCIO, Mariana. A influência do estudo de impacto de vizinhança na expedição da licença urbanística para construção de empreendimentos ou atividades com efeitos potencialmente negativos sobre o meio ambiente urbano. In: PIRES, Luis Manuel Fonseca; MENCIO, Mariana; ORTOLÁ JORGE, Antonio Carlos; ROSSO, Maximiliano; BAKOWSKI, Leandro. Estudos de Direito Urbanístico I: Licenças urbanísticas e questões polêmicas sobre as exigências da Lei de Parcelamento do Solo. São Paulo: Letras Jurídicas, 2006.

MENEZES DE ALMEIDA, Fernando Dias. Dos instrumentos da Política Urbana. In: MEDAUAR, Odete; MENEZES DE ALMEIDA, Fernando Dias (coords.). Estatuto da Cidade (Comentários à Lei Federal 10.257/2001). 2. ed. rev. atual. e ampl. São Paulo: Revista dos Tribunais, 2004.

Mecanismos de consenso no direito administrativo. In: ARAGÃO, Alexandre Santos de; MARQUES NETO, Floriano de Azevedo. Direito Administrativo e seus novos paradigmas. Belo Horizonte: Fórum, 2008.

MERCADO PACHECO, Pedro. El Analisis Económico del Derecho. Madri: Centro de Estudios Constitucionales, 1994.

MILL, John Stuart. A Liberdade: Utilitarismo. São Paulo: Martins Fontes. 2000.

MODESTO, Paulo. Notas para um debate sobre o princípio da eficiência. Revista do Serviço Público. Brasília: ENAP, ano 51, n. 2, abr/jun 2000.

MONTEIRO, Vera. Concessão. São Paulo: Malheiros, 2010.

MONTEIRO, Washington de Barros; MALUF, Carlos Alberto Dabus. Curso de Direito Civil: Direito das Coisas. 39. ed. São Paulo: Saraiva, 2009.

MORAES, Alexandre de. Direito Constitucional. 30. ed. São Paulo: Atlas, 2014.

MORAND-DEVILLER, Jacqueline. Droit Administratif. 12. ed. Paris: Montchrestien, 2011.

MOREIRA NETO, Diogo de Figueiredo. Curso de Direito Administrativo. Parte introdutória, parte geral e parte especial. 16. ed. rev. e atual. Rio de Janeiro: Forense, 2014.

. Mutações nos serviços públicos. In: WAGNER JUNIOR, Luiz Guilherme da Costa (coord.). Estudos em homenagem ao Professor Adilson Abreu Dallari. Belo Horizonte: Del Rey, 2004.

Novas Tendências da Democracia: consenso e Direito Público na virada do século - o caso brasileiro. Revista Eletrônica sobre a Reforma do Estado (RERE). Salvador: Instituto Brasileiro de Direito Público, n. 13, março/abril/maio, 2008, p. 10-11. Disponível em: <http://www. direitodoestado.com/revista/RERE-13-MAR\%C7O-2008-DIOGO-DEFIGUEIREDO-MOREIRA-NETO. PDF>. Acesso em: 22 nov. 2016. 
NOHARA, Irene Patrícia. Consensualidade e gestão democrática do interesse público no Direito Administrativo contemporâneo. Interesse Público. Belo Horizonte: Fórum, ano 15, n. 78, mar/abr 2013.

NOVIS, Mariana. O Regime Jurídico da Concessão Urbanística. Belo Horizonte: Fórum, 2011.

OLIVEIRA, Gustavo Justino de; SCHWANKA, Cristiane. A administração consensual como a nova face da administração pública no século XXI: fundamentos dogmáticos, formas de expressão e instrumentos de ação. Revista da Faculdade de Direito, Universidade de São Paulo, São Paulo, v. 104, p. 303-322, jan. 2009. ISSN 2318-8235. Disponível em: <http://www.revistas.usp.br/rfdusp/article/view/67859>. Acesso em: 26 dec. 2016.

ORGANIZAÇÃO PARA A COOPERAÇÃO E DESENVOLVIMENTO ECONÔMICO (OCDE). Relatório Brundtland. Disponível em: <https://ambiente.files.wordpress .com/2011/03/brundtland-report-our-common-future.pdf>. Acesso em: 21 nov. 2016.

ORTIZ, Gaspar Ariño. Sucessos e fracassos da regulação. REDAE, n. 3, [s. a.]. p. 14. Disponível em: <http://www.direitodoestado.com/revista/REDAE-3-AGOSTO-2005GASPAR\%20ARINO\%20ORTIZ.pdf >. Acesso em: 09 jul. 2016.

OSÓRIO, Fabio Medina. Novos rumos da gestão pública brasileira: dificuldades teóricas ou operacionais? In: WAGNER JUNIOR, Luiz Guilherme da Costa (coord.) Estudos em homenagem ao Professor Adilson Abreu Dallari. Belo Horizonte: Del Rey, 2004.

PIRES, Luis Manoel Fonseca. Limitações Administrativas à Liberdade e à Propriedade. São Paulo: Quartier Latin, 2006.

PORTO, Antonio Jose Maristrello. Análise Econômica do Direito (AED). Rio de Janeiro: FGV, 2015. Disponível em: <http://migre.me/vLB3d>. Acesso em: 13 nov. 2016.

RABELLO, Sonia. Direito Urbanístico e Direito Administrativo: Imbricação e InterRelações. Revista de Direito da Cidade. Rio de Janeiro: UERJ, v. 1, n. 1, abr. 2014. Disponível em: <http://www.e-publicacoes.uerj.br/index.php/rdc/article/view/10492/ 8264>. Acesso em: 31 mai. 2016.

REALE, Miguel. Lições preliminares de direito. 27. ed. São Paulo: Saraiva, 2002.

REISDORFER, Guilherme Fredherico Dias. Direito Urbanístico Contratual. Dos atos negociais aos contratos de gestão urbana. Rio de Janeiro: Lumen Juris, 2014.

REIS FILHO, Nestor Goulart. Urbanização e planejamento no Brasil, 1960-1983. Cadernos de Pessquisa do LAP (USP), n. 11, jan/fev 1996.

RIBEIRO, Mauricio Portugal; PRADO, Lucas Navarro. Comentários à Lei de PPP Parceria Público-Privada. Fundamentos econômicos-jurídicos. 1. ed. 2. tir. São Paulo: Malheiros, 2010. 
ROCHA, Arlindo Carvalho. Accountability na Administração Pública: Modelos Teóricos e Abordagens. Contabilidade, Gestão e Governança. Brasília: UNB Contábil, v. 14, n. 2, mai/ago 2011.

ROCHA, Arlindo Carvalho; QUINTIERE, Marcelo de Miranda Ribeiro. Auditoria Governamental: Uma abordagem metodológica da Auditoria de Gestão. Curitiba: Juruá, 2008.

ROSILHO, André; SUNDFELD, Carlos Ari. Direito e Políticas Públicas: dois mundos? In: Direito da Regulação e Políticas Públicas. São Paulo: Malheiros, 2014.

SALEME, Edson Ricardo. A licença urbanística no direito administrativo. In: MARQUES NETO, Floriano de Azevedo; MENEZES DE ALMEIDA, Fernando; NOHARA, Irene Patrícia; MARRARA, Thiago (orgs.). Direito e Administração Pública: Estudos em homenagem a Maria Sylvia Zanella di Pietro. São Paulo: Atlas, 2013.

SAMPAIO DE LACERDA, José Cândido. Manual de direito falimentar. 9. ed. Rio de Janeiro: Freitas Bastos, 1975.

SAMPAIO, Patrícia; ARAÚJO, Thiago. Previsibilidade ou Resiliência? Notas sobre a repartição de riscos em contratos administrativos. Revista de Direito da Procuradoria Geral. Rio de Janeiro: Procuradoria Geral do Estado do Rio de Janeiro, 2014.

SANTAMARÍA PASTOR, Juan Alfonso. Principios de Derecho Administrativo. 2. ed. Madrid: Editorial Centro de Estudios Ramón Areces, 2000.

SANTOS, Milton. A Urbanização Brasileira. 5. ed. São Paulo: EDUSP, 2013.

SAULE JUNIOR, Nelson. Direito Urbanístico: vias jurídicas das políticas públicas. Porto Alegre: Sergio Antonio Fabris Editor, 2007.

SCHWIND, Rafael Wallbach. Resolução consensual de controvérsias administrativas: elementos para a instituição da "Conferência de Serviço" no direito brasileiro. In: MARQUES NETO, Floriano de Azevedo; MENEZES DE ALMEIDA, Fernando; NOHARA, Irene Patrícia; MARRARA, Thiago (orgs.). Direito e Administração Pública. Estudos em homenagem a Maria Sylvia Zanella Di Pietro. São Paulo: Atlas, 2013.

SCHIEFLER, Gustavo Henrique Carvalho. Procedimento de Manifestação de Interesse (PMI). Rio de Janeiro: Lumen Juris, 2014.

SCHIRATO, Vitor Rhein. Livre Iniciativa nos Serviços Públicos. Belo Horizonte: Fórum, 2012.

SEVERI, Fabiana Cristina. Participação popular em órgãos da Administração Pública: perspectivas e desafios à luz dos debates sobre as características gerais e efetividade das instituições participativas brasileiras. In: MARQUES NETO, Floriano de Azevedo; MENEZES DE ALMEIDA, Fernando; NOHARA, Irene Patrícia; MARRARA, Thiago (orgs.). Direito e Administração Pública - Estudos em homenagem a Maria Sylvia Zanella Di Pietro. São Paulo: Atlas, 2013. 
SILVA, José Afonso da. Curso de Direito Constitucional Positivo. 25. ed. rev. e atual. São Paulo: Malheiros, 2005.

Curso de Direito Constitucional Positivo. 32. ed. São Paulo: Malheiros, 2009.

Direito Ambiental Constitucional, 10. ed. atual. São Paulo: Malheiros, 2013.

Direito Urbanístico Brasileiro. 7. ed. rev. e atual. São Paulo: Malheiros, 2012.

SILVA PEREIRA, Caio Mário da. Instituições de Direito Civil: Direitos Reais. rev. e atual. Rio de Janeiro: Forense, 2010. 4 v.

SIQUEIRA CASTRO, Carlos Roberto. O Devido Processo Legal e os Princípios da Razoabilidade e da Proporcionalidade. Rio de Janeiro: Forense, 2006.

SMOLKA, Martin O. Implementación de la Recuperación de Plusvalías en América Latina: Políticas e Instrumentos para el Desarrollo Urbano. Cambridge: Lincoln Institute of Land Policy, 2013.

SOTTO, Debora. Mais-valia urbanística e desenvolvimento urbano sustentável: uma análise jurídica. Rio de Janeiro: Lumen Juris, 2016.

SOUZA, Luciana Correia Gaspar. Município e Poder Normativo na criação de novos instrumentos urbanísticos - o Estatuto da Cidade como normativa do direito público por uma política urbana. Curitiba: Juruá, 2014.

SOUZA FILHO, Carlos Frederico Marés. Bens Culturais e sua Proteção Jurídica. 3. ed. ampl. e atual. Curitiba: Juruá, 2011.

SUNDFELD, Carlos Ari. Direito Administrativo para Céticos. São Paulo: Malheiros, 2012.

O Estatuto da Cidade e suas Diretrizes Gerais. In: DALLARI, Adilson Abreu; FERRAZ, Sérgio. Estatuto da Cidade (Comentários à Lei 10.257/2001). São Paulo: Malheiros, 2014.

Fundamentos de direito público. 6. ed. São Paulo: Malheiros, 2015.

Guia Jurídico das Parcerias Público-Privadas. In: SUNDFELD, Carlos Ari (coord.). Parcerias Público-Privadas. 2. ed. São Paulo: Malheiros, 2011.

VIEIRA DE ANDRADE, José Carlos. O dever de fundamentação expressa dos actos administrativos. Coimbra: Almedina, 1992.

VILLAÇA, Flávio. Uso do Solo Urbano. São Paulo: Fundação Prefeito Faria Lima, 1978. 